\title{
Levedura hidrolisada como fonte de nucleotídeos para leitões recém- desmamados
}

\section{Carla de Andrade ${ }^{1}$, Vivian Vezzoni de Almeida ${ }^{1}$, Leandro Batista Costa ${ }^{2}$, Bernardo Berenchtein $^{1}$, Gerson Barreto Mourão ${ }^{3}$, Valdomiro Shigueru Miyada ${ }^{3}$}

\author{
1 Programa de Pós-Graduação em Ciências - Departamento de Zootecnia, ESALQ/USP, 13418-900, Piracicaba, SP. \\ 2 Universidade Estadual de Santa Cruz, UESC, Ilhéus, BA. \\ ${ }^{3}$ Departamento de Zootecnia, ESALQ/USP, 13418-900, Piracicaba, SP
}

\begin{abstract}
RESUMO - Com este trabalho objetivou-se avaliar os efeitos de níveis de nucleotídeos em dietas para leitões recémdesmamados sobre o desempenho, a morfometria de órgãos e a histologia do epitélio intestinal. Foram utilizados 144 leitões desmamados aos 21 dias de idade e com peso médio inicial de 5,80 $\pm 0,16 \mathrm{~kg}$ em um experimento inteiramente ao acaso, com seis dietas, seis repetições por dieta e quatro animais por baia (unidade experimental). As dietas foram: Am (antimicrobiano) dieta basal com inclusão de $40 \mathrm{ppm}$ de sulfato de colistina, assim como dieta basal contendo 0, 150, 300, 450 e $600 \mathrm{ppm}$ de nucleotídeos. Ao final do experimento, foi abatido um animal de cada baia para coleta das amostras e avaliação da morfometria de órgãos e da histologia do epitélio intestinal. No período de 1 a 14 dias de experimentação, houve piora linear das características de desempenho e, no período total de 34 dias, redução linear do peso final dos animais com o aumento dos níveis de nucleotídeos na dieta. Os leitões alimentados com a dieta contendo colistina apresentaram maior comprimento do intestino delgado e menor relação altura de vilosidade:profundidade de cripta (AV:PC) no duodeno em comparação àqueles que receberam nucleotídeos. Foram observados, também, aumento linear no peso relativo do baço e na relação AV:PC e redução linear da profundidade de cripta no duodeno dos animais com a adição de nucleotídeos na dieta. Assim, embora não tenha promovido melhora no desempenho, a adição de até 600 ppm de nucleotídeos em dietas complexas melhora a morfometria de órgãos e a histologia do epitélio intestinal de leitões recém-desmamados.
\end{abstract}

Palavras-chave: antimicrobianos, desempenho, histologia, intestino, morfometria, suínos

\section{Hydrolyzed yeast as source of nucleotides for weanling pigs}

\begin{abstract}
The objective of this work was to evaluate the effects of levels of nucleotides in diets for weanling pigs on performance, organs morphometry and histology of intestinal epithelium. One hundred and forty-four pigs weaned at 21 days of age and with $5.80 \pm 0.16 \mathrm{~kg}$ initial live weight were used in a completely randomized experimental design with six diets, six replications per diet and four animals per pen (experimental unit). Diets were: Am - antimicrobial: basal diet with 40 ppm of colistin sulfate and basal diet with $0,150,300,450$ and $600 \mathrm{ppm}$ of nucleotides. At the end of the experimental period, one animal of each pen was slaughtered to evaluate morphometry of the organs and intestinal epithelium histology. From day 1 to day 14 of the experimental period, performance traits worsened linearly and for the total experimental period of 34 days, a linear reduction of final live weight was observed when levels of dietary nucleotides were increased. Pigs fed diet with colistin showed greater length of small intestine and lower villus height:crypt depth ratio (AV:PC) of duodenum when compard to those fed nucleotides. Also, a linear increase of relative weight of spleen, as well as a linear increase of AV:PC and linear reduction of crypt depth of duodenum were observed with the addition of nucleotides in the diet. Therefore, although the addition up to $600 \mathrm{ppm}$ of nucleotides in complex diets did not improve performance, it improves morphometry of the organs and intestinal epithelium histology of weanling pigs.
\end{abstract}

Key Words: antimicrobial, histology, intestine, morphometry, performance, swine

\section{Introdução}

A tecnificação do sistema de produção de suínos tem proporcionado melhora na produtividade das porcas, em decorrência da redução do período de amamentação para três a quatro semanas (Costa et al., 2007). A retirada da dieta líquida e altamente digestível, aliada ao início da ingestão de dieta sólida, ainda de baixa digestibilidade para o leitão, aumenta o risco de diarreias (Viola \& Vieira, 2003), distúrbios no balanço da microbiota intestinal (Ravindran \& Kornegay, 1993) e risco de mortalidade, além de onerar os custos com medicamentos (Viola \& Vieira, 2003). 
O setor de produção animal tem feito uso frequente de vários antimicrobianos em dosagens subclínicas, tornando-se líder mundial na utilização desses aditivos como melhoradores de desempenho para diferentes espécies animais (Bellaver, 2000). Entretanto, seu uso tem sido restringido ou banido em diversos países, em virtude da possibilidade de desenvolvimento de resistência bacteriana cruzada (Silva et al., 2000; Pedroso et al., 2005) e da emergente exigência dos países importadores de carne em adquirir produtos livres de resíduos de antimicrobianos (Silva, 2000). Com isso, pesquisadores têm se motivado em buscar alternativas que reduzam o impacto da retirada dos antimicrobianos e que, ao mesmo tempo, garantam máximo crescimento dos animais sem afetar a qualidade do produto final (Oetting et al., 2006). Entre essas alternativas, merece destaque o uso de enzimas, probióticos, prebióticos, extratos vegetais, ácidos orgânicos e, mais recentemente, os nucleotídeos (Stein \& Kil, 2006).

Os nucleotídeos são componentes intracelulares de baixo peso molecular, integrados a numerosos processos metabólicos e essenciais para todas as células (Mateo et al., 2004). Os benefícios de seu uso como melhoradores do desempenho de suínos podem estar relacionados ao aumento das secreções digestivas (Witte et al., 1991), à melhora na digestibilidade e absorção dos nutrientes (Budiño et al., 2004), à modificação da microbiota intestinal, ao estímulo ao sistema imune e desenvolvimento, à maturação e ao reparo do trato gastrintestinal (Uauy et al., 1994).

Desse modo, realizou-se este trabalho com o objetivo de avaliar os efeitos do fornecimento de nucleotídeos na dieta sobre o desempenho, a morfometria de órgãos e a histologia do epitélio intestinal de leitões recémdesmamados.

\section{Material e Métodos}

Foram utilizados 144 leitões desmamados aos 21 dias de idade, com peso médio inicial e final de, respectivamente, $5,80 \pm 0,16$ e 17,19 $\pm 1,32 \mathrm{~kg}$. Como a creche experimental possui 20 baias, foram realizados dois grupos de experimentos, cada um com 72 animais. O delineamento experimental foi inteiramente ao acaso, com seis dietas, seis repetições por dieta e quatro animais por unidade experimental (dois machos castrados e duas fêmeas).

As dietas experimentais foram: Am (antimicrobiano)dieta basal com inclusão de $40 \mathrm{ppm}$ de sulfato de colistina, assim como dieta basal contendo 0, 150,300, 450 e 600 ppm de nucleotídeos. Foi utilizado um produto comercial, obtido pela hidrólise da levedura Saccharomyces cerevisiae, com 3,0 a $3,5 \%$ de nucleotídeos e nucleotídeos.

Foram utilizadas duas dietas basais: a pré-inicial fornecida do $1^{\circ}$ ao $14^{\circ}$ dia (Tabela 1 ) e a inicial do $14^{\circ}$ ao $34^{\circ}$ dias de experimentação (Tabela 2), atendendo às recomendações de Rostagno et al. (2005). Os animais receberam, durante o período experimental, ração e água à vontade.

Para determinação das características de desempenho (consumo diário de ração, ganho diário de peso e conversão alimentar), foram realizadas pesagens dos animais e das rações fornecidas e desperdiçadas ao $1^{\circ} \stackrel{0}{ }, 14^{\circ}$ e $34^{\circ}$ dias.

Ao final do experimento, foi abatido um animal por baia (unidade experimental), após jejum de sólidos de 14 horas, para avaliação da morfometria de órgãos e da histologia do epitélio intestinal. $\mathrm{O}$ animal escolhido foi aquele com o peso vivo mais próximo do peso médio dos animais de cada tratamento, independente do sexo. Após o sacrifício, foi aberta a cavidade abdominal por incisão longitudinal, retirados e pesados os órgãos digestórios (estômago vazio, pâncreas, fígado e intestino delgado vazio) e o baço e, ainda, foi feita a medição do comprimento do intestino delgado. Nas análises de histologia intestinal, segmentos de cerca de $3 \mathrm{~cm}$ de comprimento do duodeno (retirados a $15 \mathrm{~cm}$ do esfíncter estomacal) e do jejuno (retirados a 1,5 m da junção do íleo com o intestino grosso), foram lavados com solução salina ( $\mathrm{NaCl}-0,9 \%)$ e fixados em solução de formol $(10,0 \%)$ tamponado. A seguir, foram enviados ao Laboratório de Matriz Extracelular do Departamento de Morfologia do Instituto de Biociências da UNESP, campus de Botucatu, São Paulo, para posterior análise com a técnica de microscopia óptica. Simultaneamente à retirada de amostras para análise de microscopia óptica, foram retiradas amostras de $0,25 \mathrm{~cm}^{2}(0,50 \times 0,50 \mathrm{~cm})$ do duodeno e do jejuno para análise em microscopia eletrônica de varredura. No momento da coleta, as amostras foram lavadas com solução salina ( $\mathrm{NaCl}-0,9 \%)$, mergulhadas em solução fixadora de Karnovisk por duas horas, cortadas e armazenadas em definitivo na mesma solução. Posteriormente, foram transportadas ao NAP/MEPA - Núcleo de Apoio à Pesquisa em Microscopia Eletrônica Aplicada a Agricultura, na ESALQ/USP, em Piracicaba, São Paulo.

Os dados obtidos foram analisados considerando-se dois grupos de animais no tempo devido à heterogeneidade de variâncias entre os grupos. Os graus de liberdade do fator nível foram decompostos em seus componentes individuais (linear, quadrático e cúbico), através dos polinômios ortogonais. Além disso, foram testados três contrastes de importância prática pelo PROC MIXED do SAS (Statistical Analysis System, 2001). 
Tabela 1 - Composição percentual e valores calculados das dietas pré-iniciais

\begin{tabular}{|c|c|c|c|c|c|c|}
\hline & \multirow[t]{2}{*}{ Antimicrobiano } & \multicolumn{5}{|c|}{ Nível de nucleotídeos (ppm) } \\
\hline & & 0 & 150 & 300 & 450 & 600 \\
\hline Milho (\%) & 49,80 & 49,80 & 48,95 & 48,94 & 48,92 & 48,90 \\
\hline Farelo de soja $46 \%(\%)$ & 26,00 & 26,00 & 24,91 & 23,88 & 22,85 & 21,82 \\
\hline Produto lácteo $(\%)^{2}$ & 5,65 & 5,65 & 7,86 & 8,98 & 10,10 & 11,23 \\
\hline Açúcar (\%) & 2,00 & 2,00 & 2,00 & 2,00 & 2,00 & 2,00 \\
\hline L-lisina. $\mathrm{HCl} \quad 78 \%(\%)$ & 0,80 & 0,80 & 0,74 & 0,76 & 0,77 & 0,79 \\
\hline L-triptofano $98 \%(\%)$ & 0,06 & 0,06 & 0,06 & 0,06 & 0,06 & 0,07 \\
\hline Calcário $(\%)$ & 0,71 & 0,71 & 0,66 & 0,65 & 0,64 & 0,63 \\
\hline Fosfato bicálcico (\%) & 1,73 & 1,73 & 1,91 & 1,94 & 1,97 & 1,99 \\
\hline Caulim $(\%)$ & - & 0,004 & - & - & - & - \\
\hline Antimicrobiano $(\%)^{3}$ & 0,004 & - & - & - & - & - \\
\hline Levedura hidrolisada (\%) & - & - & 0,50 & 1,00 & 1,50 & 2,00 \\
\hline Energia metabolizável, kcal/kg & 3325 & 3325 & 3352 & 3356 & 3360 & 3365 \\
\hline Proteína bruta, \% & 19,42 & 19,42 & 19,31 & 19,23 & 19,14 & 19,05 \\
\hline Cálcio, \% & 0,88 & 0,88 & 0,92 & 0,93 & 0,93 & 0,93 \\
\hline Fósforo, \% & 0,70 & 0,70 & 0,73 & 0,73 & 0,73 & 0,74 \\
\hline Lactose, \% & 11,00 & 11,00 & 11,32 & 11,34 & 11,35 & 11,37 \\
\hline Lisina digestível, \% & 1,55 & 1,55 & 1,51 & 1,51 & 1,50 & 1,50 \\
\hline Metionina digestível, \% & 0,43 & 0,43 & 0,41 & 0,41 & 0,41 & 0,41 \\
\hline Treonina digestível, \% & 0,96 & 0,96 & 0,90 & 0,90 & 0,89 & 0,89 \\
\hline Triptofano digestível, \% & 0,26 & 0,26 & 0,25 & 0,25 & 0,25 & 0,25 \\
\hline
\end{tabular}

Tabela 2 - Composição percentual e valores calculados das dietas iniciais

\begin{tabular}{|c|c|c|c|c|c|c|}
\hline & \multirow[t]{2}{*}{ Antimicrobiano } & \multicolumn{5}{|c|}{ Nível de nucleotídeos (ppm) } \\
\hline & & 0 & 150 & 300 & 450 & 600 \\
\hline Milho (\%) & 63,00 & 63,00 & 61,60 & 62,32 & 61,51 & 61,49 \\
\hline Farelo de soja $46 \%(\%)$ & 26,00 & 26,00 & 26,00 & 25,00 & 24,82 & 23,80 \\
\hline Produto lácteo $(\%)^{2}$ & 0,61 & 0,61 & 2,95 & 2,31 & 3,41 & 4,52 \\
\hline Açúcar (\%) & 2,00 & 2,00 & 2,00 & 2,00 & 2,00 & 2,00 \\
\hline L-lisina. $\mathrm{HCl} \quad 78 \%(\%)$ & 0,30 & 0,30 & 0,17 & 0,21 & 0,20 & 0,22 \\
\hline Calcário $(\%)$ & 0,37 & 0,37 & 0,61 & 0,62 & 0,62 & 0,60 \\
\hline Fosfato bicálcico (\%) & 1,80 & 1,80 & 1,52 & 1,51 & 1,52 & 1,55 \\
\hline Caulim $(\%)$ & - & 0,004 & - & - & - & - \\
\hline Antimicrobiano $(\%)^{3}$ & 0,004 & - & - & - & - & - \\
\hline Levedura hidrolisada (\%) & - & - & 0,50 & 1,00 & 1,50 & 2,00 \\
\hline Cloreto de colina $(\%)$ & 0,10 & 0,10 & 0,10 & 0,10 & 0,10 & 0,10 \\
\hline Proteína bruta, \% & 18,00 & 18,00 & 18,24 & 18,00 & 18,21 & 18,12 \\
\hline Cálcio, \% & 0,70 & 0,70 & 0,73 & 0,73 & 0,73 & 0,74 \\
\hline Fósforo, \% & 0,66 & 0,66 & 0,61 & 0,61 & 0,61 & 0,61 \\
\hline Lactose, \% & 4,00 & 4,00 & 4,12 & 4,11 & 4,13 & 4,14 \\
\hline Lisina digestível, \% & 1,00 & 1,00 & 0,99 & 0,99 & 0,99 & 0,99 \\
\hline Metionina digestível, \% & 0,27 & 0,27 & 0,27 & 0,27 & 0,27 & 0,27 \\
\hline Treonina digestível, \% & 0,69 & 0,69 & 0,60 & 0,60 & 0,60 & 0,60 \\
\hline Triptofano digestível, \% & 0,19 & 0,19 & 0,19 & 0,18 & 0,18 & 0,18 \\
\hline
\end{tabular}




\section{Resultados e Discussão}

No período de 1 a 14 dias de experimentação (Tabela 3), com a adição de nucleotídeos na dieta, houve piora linear $(\mathrm{P}<0,01)$ de todas as características de desempenho: peso vivo aos $14 \operatorname{dias}\left(\mathrm{P} 14=-0,0011 \mathrm{x}+7,662, \mathrm{R}^{2}=0,47\right)$, consumo diário de ração $\left(C D R=-0,00005 x+0,2364, R^{2}=0,42\right)$, ganho de peso diário $\left(\mathrm{GPD}=-0,00008 \mathrm{x}+0,1274, \mathrm{R}^{2}=0,61\right) \mathrm{e}$ conversão alimentar $\left(C A=0,0008 x+1,594, R^{2}=0,46\right)$. Por outro lado, no período total de 34 dias de experimentação (Tabela 3), os nucleotídeos acarretaram redução linear $(\mathrm{P}=0,03)$ apenas no peso vivo final dos leitões (P34 = $\left.-0,0017 \mathrm{x}+18,172, \mathrm{R}^{2}=0,39\right)$, sem afetar $(\mathrm{P}>0,05)$ as demais características de desempenho.

Aos 14 dias de experimentação, um dos fatores que afetou negativamente o peso aos 14 dias e o ganho de peso diário dos leitões alimentados com dietas suplementadas com nucleotídeos foi, possivelmente, a redução no consumo diário de ração desses animais. A menor ingestão de ração pelos animais normalmente acarreta menor ganho de peso e menor peso vivo (Landell Filho et al., 1994; Costa, 2004). Níveis de leveduras superiores a $13 \%$ como fonte proteica para leitões recém-desmamados provocaram redução no consumo diário de ração, sem afetar, no entanto, o ganho de peso dos animais (Castilho et al., 2004). Esse resultado pode ser explicado pela menor palatabilidade da dieta com a inclusão de levedura. Neste estudo, a inclusão de até $2 \%$ de levedura ocasionou redução no consumo diário de ração, embora, a adição de níveis similares de levedura na dieta de leitões, até $0,8 \%$ (Garcia, 2007) e até 3\% (Oliveira Junior, 2008), não tenha afetado o consumo diário de ração.

Embora alguns autores (Veum \& Bowman, 1973; Nunes, 1988; Santos et al., 1988; Tibbetts, 2002; Costa, 2004) apontem a piora na conversão alimentar como consequência do pior valor nutritivo da dieta, não há qualquer evidência de que o fornecimento de nucleotídeos tenha causado esse efeito, uma vez que os níveis utilizados foram muito baixos (até 2,0\% de levedura hidrolisada). Por outro lado, têm sido relatados até mesmo benefícios da levedura na conversão alimentar (Araújo et al., 2006; Pelícia et al., 2010; Barbalho, 2009), sugerindo que diferentes processos de obtenção e secagem podem afetar a qualidade da levedura e dos seus produtos, seja pela deficiência seja pelo excesso de nutrientes (Amorim \& Lopes, 2009), pela concentração de minerais e impurezas, além da grande variação na sua composição química (Butolo, 2002).

Apesar da piora nas características de desempenho dos leitões alimentados com nucleotídeos, o nível de $150 \mathrm{ppm}$ de nucleotídeos proporcionou, no período de 1 a 14 dias, aumento relativo de $3,17 \%$ no peso aos 14 dias, de $13,45 \%$ no consumo diário de ração e de $10,66 \%$ no ganho de peso diário em relação à dieta controle $(0 \mathrm{ppm}$ de nucleotídeo) e aumento de 3,30\% no peso aos 14 dias, de $12,40 \%$ no consumo diário de ração e de $14,41 \%$ no ganho de peso dos leitões em comparação à dieta com antimicrobiano. Aos 34 dias, foi observada, embora nãosignificativa $(\mathrm{P}>0,05)$, melhora de 2,26 e $3,0 \%$ no peso final com a inclusão de $150 \mathrm{ppm}$ de nucleotídeos na dieta, em comparação à dieta controle e à dieta com antimicrobiano, respectivamente. Esses resultados podem ser indicativos de efeito benéfico do uso de nucleotídeos em níveis próximos a $150 \mathrm{ppm}$ no desempenho de leitões (Tabela 3). Outros estudos comprovam efeito positivo da inclusão de nucleotídeos sobre o desempenho de leitões (Yu et al., 2002) e frangos de corte (Rutz et al., 2006; Barbalho, 2009). Os resultados deste estudo diferem, no entanto, daqueles

Tabela 3 - Desempenho de leitões nos períodos pré-inicial (1 a 14 dias) e inicial (14 a 34 dias) alimentados com dietas contendo nucleotídeos

\begin{tabular}{|c|c|c|c|c|c|c|c|c|c|c|}
\hline & \multirow[t]{2}{*}{ Antimicrobiano } & \multicolumn{5}{|c|}{ Nível de nucleotídeos (ppm) } & \multicolumn{3}{|c|}{ Contrastes $^{2}$} & \multirow[t]{2}{*}{$\mathrm{CV}^{3}(\%)$} \\
\hline & & 0 & 150 & 300 & 450 & 600 & $\mathrm{C} 1$ & $\mathrm{C} 2$ & $\mathrm{C} 3$ & \\
\hline \multicolumn{11}{|l|}{ Período de 1 a 14 dias } \\
\hline Peso aos 14 dias $(\mathrm{kg})^{1}$ & 7,57 & 7,58 & 7,82 & 6,94 & 7,34 & 7,02 & NS & $<0,01$ & $<0,01$ & 6,71 \\
\hline Consumo diário de ração $(\mathrm{kg})^{1}$ & 0,225 & 0,223 & 0,253 & 0,209 & 0,213 & 0,202 & NS & NS & NS & 13,31 \\
\hline Ganho diário de peso $(\mathrm{kg})^{1}$ & 0,118 & 0,122 & 0,135 & 0,080 & 0,096 & 0,079 & NS & $<0,01$ & $<0,01$ & 32,55 \\
\hline \multicolumn{11}{|l|}{ Período de 1 a 34 dias } \\
\hline Peso aos 34 dias $(\mathrm{kg})^{1}$ & 17,97 & 18,09 & 18,50 & 16,85 & 17,56 & 17,26 & NS & NS & NS & 8,04 \\
\hline Consumo diário de ração $(\mathrm{kg})$ & 0,564 & 0,575 & 0,566 & 0,508 & 0,551 & 0,515 & NS & NS & NS & 17,79 \\
\hline Ganho diário de peso $(\mathrm{kg})$ & 0,331 & 0,359 & 0,360 & 0,316 & 0,334 & 0,328 & NS & NS & NS & 12,16 \\
\hline Conversão alimentar & 1,58 & 1,61 & 1,74 & 1,68 & 1,78 & 1,70 & NS & NS & NS & 16,95 \\
\hline
\end{tabular}


relatados por Araújo et al. (2006) e Garcia (2007), que não observaram efeito positivo no desempenho de suínos alimentados com nucleotídeos.

Quando comparadas as dietas com $0 \mathrm{ppm}$ de nucleotídeos e com antimicrobiano, não foi encontrada diferença $(\mathrm{P}>0,05)$ nas características de desempenho. De acordo com Menten \& Miyada (1995) e Costa (2009), em condições favoráveis ao desempenho dos leitões - como o uso das dietas complexas, o baixo desafio sanitário, o manejo e o ambiente adequados -, dificilmente um aditivo propicia efeitos benéficos e, às vezes, pode até prejudicar o desempenho dos leitões.

O peso relativo do baço aumentou de forma linear $(\mathrm{P}=0,005)$ de acordo com os níveis de nucleotídeos (Tabela 4) nas dietas $\left(\mathrm{Y}=0,0001 \mathrm{x}+0,198, \mathrm{R}^{2}=0,64\right)$. Esses dados contrariam relatos de Garcia (2007) de que o peso relativo do baço não foi afetado pelo fornecimento de nucleotídeos em níveis de até $0,8 \%$ na dieta de leitões. $O$ aumento do peso relativo do baço pode ser associado ao possível estímulo à imunidade dos leitões recém-desmamados quando alimentados com nucleotídeos. Carver (1994), estudando a adição de nucleotídeos em dietas para ratos recémdesmamados, observou, nas células do baço, maior ativação dos macrófagos e maior produção de interleucina-2, uma proteína que induz a maturação de linfócitos B e linfócitos $\mathrm{T}$, que auxiliam no sistema imune do animal. Embora o mecanismo de ação dos nucleotídeos dietéticos sobre a imunidade do animal não esteja bem esclarecido, tem-se sugerido que eles podem propiciar aumento no peso do baço, órgão responsável pela produção de leucócitos e pela maior produção de anticorpos (Carver, 1994).

Há relatos de que a inclusão de nucleotídeos em dietas para leitões pode propiciar maior peso relativo do fígado desses animais (Carver, 1994; Garcia, 2007), uma vez que os nucleotídeos e os nucleosídeos podem promover o crescimento e a regeneração dos hepatócitos, além de desempenhar importante papel na síntese de glicogênio (Carver, 1994; Grimble, 1994). Entretanto, neste experimento, não foi observada diferença no peso relativo do fígado dos leitões $(\mathrm{P}>0,05)$ com a adição de nucleotídeos na dieta dos animais.

Os animais alimentados com a dieta com antimicrobiano apresentaram maior $(\mathrm{P}<0,01)$ comprimento do intestino delgado, todavia, esse maior comprimento não afetou ( $\mathrm{P}>0,05)$ o peso dos órgãos nem o desempenho dos leitões. Em trabalhos anteriores, a adição de antibióticos na dieta de frangos (Rizzo et al., 2010) e suínos (Costa et al., 2007) resultou em menor comprimento e menor peso relativo do intestino delgado desses animais. Os autores atribuíram esses resultados aos benefícios da inclusão dos antibióticos nas dietas, como a redução de inflamações, decorrente do controle de patógenos aderidos ao epitélio intestinal, a redução na espessura da parede intestinal e o aumento na eficiência de absorção dos nutrientes, favorecendo, assim, o desempenho dos animais. Gomes et al. (2007), comparando a morfologia dos órgãos de suínos de diferentes linhagens, relataram que maiores pesos dos órgãos digestórios, não digestórios e maior comprimento do intestino delgado podem afetar negativamente a eficiência alimentar, uma vez que o animal utiliza, para a sua manutenção, a energia que seria destinada à produção.

Os pesos relativos dos demais órgãos estudados não diferiram $(\mathrm{P}>0,05)$ entre as dietas, o que corrobora outros trabalhos realizados anteriormente (Jin et al., 1994; Pelícia et al., 2010). Segundo Rao \& McCracken (1992), os pesos dos órgãos variam com o consumo de energia e/ou proteína, sugerindo que, sendo similar o consumo de ração dos animais, os pesos dos órgãos possivelmente não serão influenciados pelas dietas. Além disso, não foi observada, neste trabalho, qualquer irritação da mucosa intestinal nem

Tabela 4 - Peso relativo (\% do peso vivo) dos órgãos digestórios e baço, comprimento, comprimento relativo e relação peso:comprimento do intestino delgado de leitões recém-desmamados

\begin{tabular}{|c|c|c|c|c|c|c|c|c|c|c|}
\hline \multirow[t]{2}{*}{ Variável } & \multirow[t]{2}{*}{ Antimicrobiano } & \multicolumn{5}{|c|}{ Nível de nucleotídeos (ppm) } & \multicolumn{3}{|c|}{ Contrastes $^{2}$} & \multirow[t]{2}{*}{$\mathrm{CV}^{3}(\%$} \\
\hline & & 0 & 150 & 300 & 450 & 600 & $\mathrm{C} 1$ & $\mathrm{C} 2$ & $\mathrm{C} 3$ & \\
\hline Peso aos 34 dias (kg) & 17,97 & 18,09 & 18,50 & 16,85 & 17,56 & 17,26 & NS & NS & NS & 8,04 \\
\hline Estômago (\%) & 0,67 & 0,66 & 0,68 & 0,71 & 0,75 & 0,63 & NS & NS & NS & 13,38 \\
\hline Pâncreas $(\%)$ & 0,16 & 0,18 & 0,19 & 0,18 & 0,14 & 0,16 & NS & NS & NS & 27,82 \\
\hline Fígado $(\%)$ & 2,50 & 2,43 & 2,48 & 2,73 & 2,87 & 2,65 & NS & NS & NS & 10,96 \\
\hline Intestino delgado (\%) & 4,90 & 4,31 & 4,30 & 4,80 & 4,94 & 4,50 & NS & NS & NS & 13,0 \\
\hline Baço $(\%)^{1}$ & 0,20 & 0,17 & 0,21 & 0,22 & 0,28 & 0,24 & NS & $<0,01$ & NS & 20,99 \\
\hline Comprimento intestino delgado (m) & 17,45 & 16,08 & 16,62 & 15,97 & 16,16 & 16,04 & $<0,01$ & NS & $<0,01$ & 6,65 \\
\hline Comprimento relativo (m/kg PV) & 0,987 & 0,939 & 0,952 & 0,927 & 0,937 & 0,957 & NS & NS & NS & 8,34 \\
\hline Peso:comprimento $(\mathrm{kg} / \mathrm{m})$ & 0,050 & 0,048 & 0,047 & 0,050 & 0,053 & 0,049 & NS & NS & NS & 10,5 \\
\hline
\end{tabular}

${ }^{1}$ Efeito linear significativo $(\mathrm{P}=0,005)$.

2 Contraste: $\mathrm{C} 1=0 \times$ antimicrobianos; $\mathrm{C} 2=0 \times$ média de $150,300,450$ e 600 ppm de nucleotídeos; $\mathrm{C} 3=$ antimicrobianos $\times$ média de $150,300,450$ e 600 ppm de nucleotídeos.

${ }^{3}$ Coeficiente de variação.

$\mathrm{NS}=$ não-significativo $(\mathrm{P}>0,05)$ 
infecção ou injúria, que pudesse influenciar o peso dos órgãos desses animais.

Houve redução linear $(\mathrm{P}<0,01)$ da profundidade de cripta (PC) e aumento linear $(\mathrm{P}<0,01)$ da relação altura de vilosidade:profundidade de cripta (AV:PC) no duodeno dos leitões com a inclusão de nucleotídeos na dieta (Tabela 5).

A redução linear da profundidade de criptas $(\mathrm{PC}=$ $\left.-0,0838 \mathrm{x}+255,21, \mathrm{R}^{2}=0,82\right)$ no duodeno dos leitões que receberam nucleotídeos nas dietas pode ser um indicativo da menor taxa de proliferação das células da cripta. $\mathrm{Na}$ verdade, isso pode ter sido ocasionado pela menor taxa de renovação das células maduras do epitélio intestinal, fato que estaria favorecendo a digestão e absorção de nutrientes (Smith, 1984, citado por Cera et al., 1988). Esses resultados estão de acordo com outros trabalhos realizados com ratos jovens (Uauy et al., 1990) e suínos (Yu et al., 2002). Por outro lado, Bueno et al. (1994) encontraram maior profundidade de criptas no duodeno de ratos recémdesmamados alimentados com nucleotídeos quando induzidos a diarreia crônica. Os nucleotídeos, nesse caso, não promoveram benefícios à morfologia intestinal desses animais.

Os valores de altura de vilosidades no duodeno dos leitões, por sua vez, foram similares entre os grupos $(\mathrm{P}>0,05)$. Com a inclusão de nucleotídeos nas dietas, pode ter havido menor perda de células na região apical dos vilos (Pluske et al., 1997), ou seja, menor turnover das células epiteliais, mantendo adequadas a produção de enzimas e a digestão e absorção dos nutrientes (Cera et al., 1988).

O aumento linear da relação altura de vilosidades:profundidade de criptas (AV:PC $=0,001 \mathrm{x}+$ $\left.2,192, \mathrm{R}^{2}=0,73\right)$ no duodeno dos leitões que receberam os nucleotídeos na dieta pode ser explicado pelo mesmo fato relatado por Tucci et al. (2004), ou seja, a menor taxa de reposição celular proporciona maior relação altura de vilosidades:profundidade de criptas, uma evidência da integridade dos vilos e enterócitos maduros e funcionais. Outros autores afirmam que a maior relação altura de vilosidades:profundidade de criptas está relacionada ao aumento na capacidade de digestão e absorção dos nutrientes da dieta, refletindo em melhor desempenho (Tibbets, 2002; Maribo, 2003; Rutz et al., 2006; Costa, 2009). Neste estudo, entretanto, a inclusão de nucleotídeos nas dietas, embora tenha melhorado as características morfológicas (AV:PC e PC) no duodeno dos animais, não melhorou o desempenho dos leitões.

Para as variáveis altura de vilosidades (AV), profundidade de criptas (PC) e relação AV:PC no jejuno, não foram detectadas diferenças $(\mathrm{P}>0,05)$ entre as dietas. Esses resultados estão de acordo com os de Abreu et al. (2007) e Garcia (2007), mas diferem, por outro lado, daqueles reportados por Bueno et al. (1994), que encontraram maior relação AV:PC no jejuno de ratos recém-desmamados alimentados com dietas suplementadas com nucleotídeos.

A densidade das vilosidades intestinais, tanto do duodeno como do jejuno dos animais, não foi influenciada ( $\mathrm{P}>0,05)$ pelas dietas. De acordo com Boleli et al. (2002), a capacidade de absorção dos nutrientes é proporcional à densidade e ao tamanho das vilosidades intestinais. No entanto, outros autores suplementaram dietas para leitões com aditivos como ácido fumárico e suas combinações (Gomes et al., 2007), probióticos (Budiño et al., 2004) e mananoligossacarídeos (Tucci et al., 2004) e relataram que os animais obtiveram desempenho superior aos dos animais do grupo controle e não notaram influência na densidade dos vilos.

Tabela 5 - Altura das vilosidades intestinais, profundidade de criptas, relação altura de vilosidade:profundidade de cripta e densidade de vilos do duodeno e do jejuno de leitões recém-desmamados

\begin{tabular}{|c|c|c|c|c|c|c|c|c|c|c|}
\hline \multirow[t]{2}{*}{ Variável } & \multirow[t]{2}{*}{ Antimicrobiano } & \multicolumn{5}{|c|}{ Nível de nucleotídeos (ppm) } & \multicolumn{3}{|c|}{ Contrastes $^{2}$} & \multirow[t]{2}{*}{$\mathrm{CV}^{3}(\%)$} \\
\hline & & 0 & 150 & 300 & 450 & 600 & $\mathrm{C} 1$ & $\mathrm{C} 2$ & $\mathrm{C} 3$ & \\
\hline \multicolumn{11}{|l|}{ Duodeno } \\
\hline Altura de vilosidades $(\mu \mathrm{m})$ & 500,7 & 517,4 & 562,9 & 568,6 & 519,5 & 548,8 & NS & NS & NS & 18,50 \\
\hline Profundidade de cripta $(\mu \mathrm{m})^{1}$ & 257,6 & 245,1 & 257,3 & 230,8 & 212,1 & 204,8 & NS & NS & NS & 17,04 \\
\hline $\mathrm{AV}: \mathrm{PC}^{1,4}$ & 1,90 & 2,23 & 2,23 & 2,65 & 2,45 & 2,84 & NS & NS & $<0,01$ & 18,29 \\
\hline Densidade de vilos 5 & 32,2 & 30,3 & 31,4 & 25,5 & 29,1 & 36,4 & NS & NS & NS & 26,29 \\
\hline \multicolumn{11}{|l|}{ Jejuno } \\
\hline Altura de vilosidades $(\mu \mathrm{m})$ & 601,6 & 561,4 & 573,1 & 627,6 & 554,9 & 597,8 & NS & NS & NS & 16,24 \\
\hline Profundidade de cripta $(\mu \mathrm{m})$ & 271,0 & 215,8 & 263,5 & 268,5 & 249,6 & 259,0 & NS & NS & NS & 16,29 \\
\hline $\mathrm{AV}: \mathrm{PC}^{4}$ & 2,20 & 2,53 & 2,11 & 2,34 & 2,18 & 2,27 & NS & NS & NS & 19,17 \\
\hline Densidade de vilos ${ }^{5}$ & 32,5 & 27,6 & 31,4 & 29,4 & 30,7 & 36,0 & NS & NS & NS & 24,98 \\
\hline
\end{tabular}


As vilosidades do duodeno dos animais (Figura 1) que receberam as dietas com antimicrobianos e aquelas com 0,450 e $600 \mathrm{ppm}$ de nucleotídeos apresentaram-se alongadas, com formato de dedo e com poucas deformidades, podendo ser classificadas como normais. As vilosidades dos leitões alimentados com as dietas com 150 e 450 ppm de nucleotídeos apresentaram-se ligeiramente achatadas. No entanto, quando avaliadas a altura e a densidade das vilosidades intestinais dos animais, verificou-se que essas duas dietas ( 150 e $450 \mathrm{ppm}$ ) foram similares ou até mesmo superiores às observadas nos leitões alimentados com as demais dietas. Isso pode ter sido consequência de outros fatores, que não as dietas, durante o preparo das amostras (manipulação excessiva e/ou problemas na fixação). No jejuno dos leitões (Figura 2), os vilos apresentaram-se lameliformes, com aspecto folheáceo, típico do segmento, semelhantes àqueles relatados nos estudos realizados por Bueno et al. (1994).
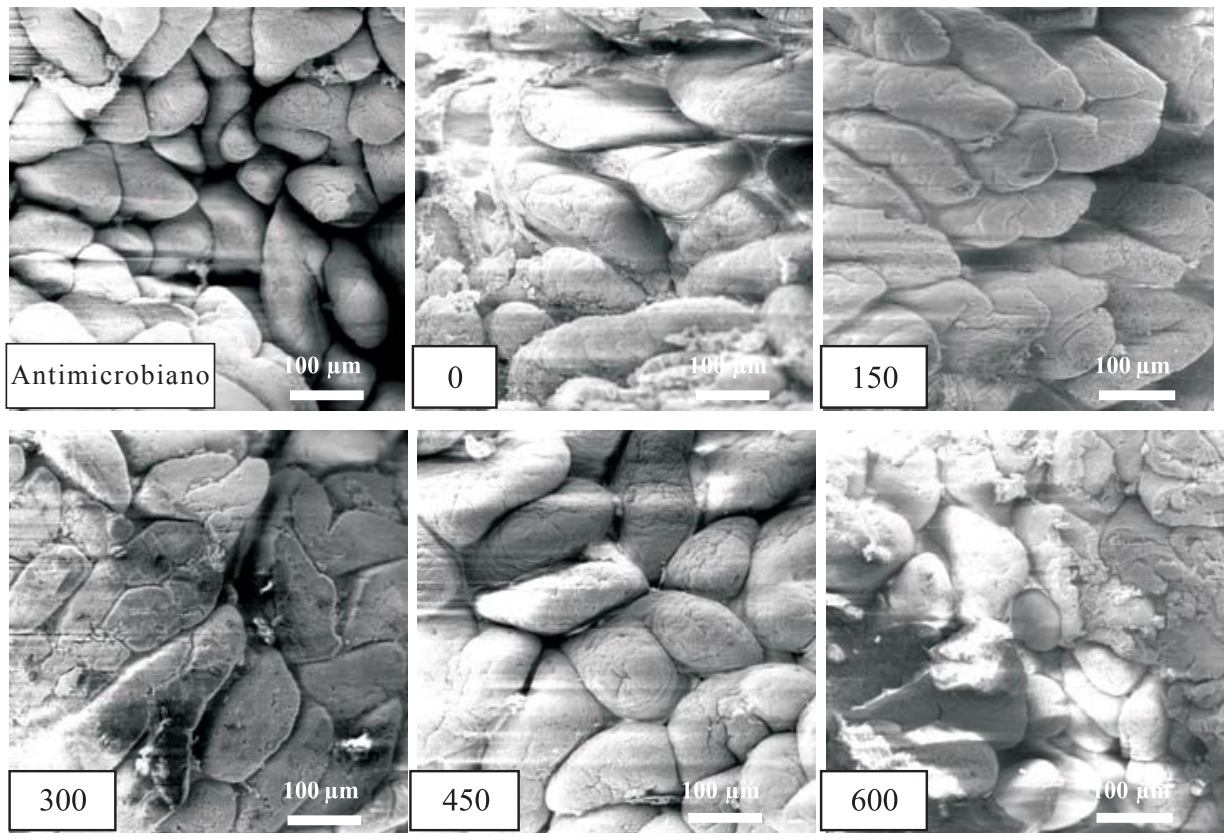

Figura 1 - Eletronmicrografia de varredura do duodeno de leitões alimentados com dietas contendo antimicrobianos e $0,150,300,450$ ou 600 ppm de nucleotídeos.
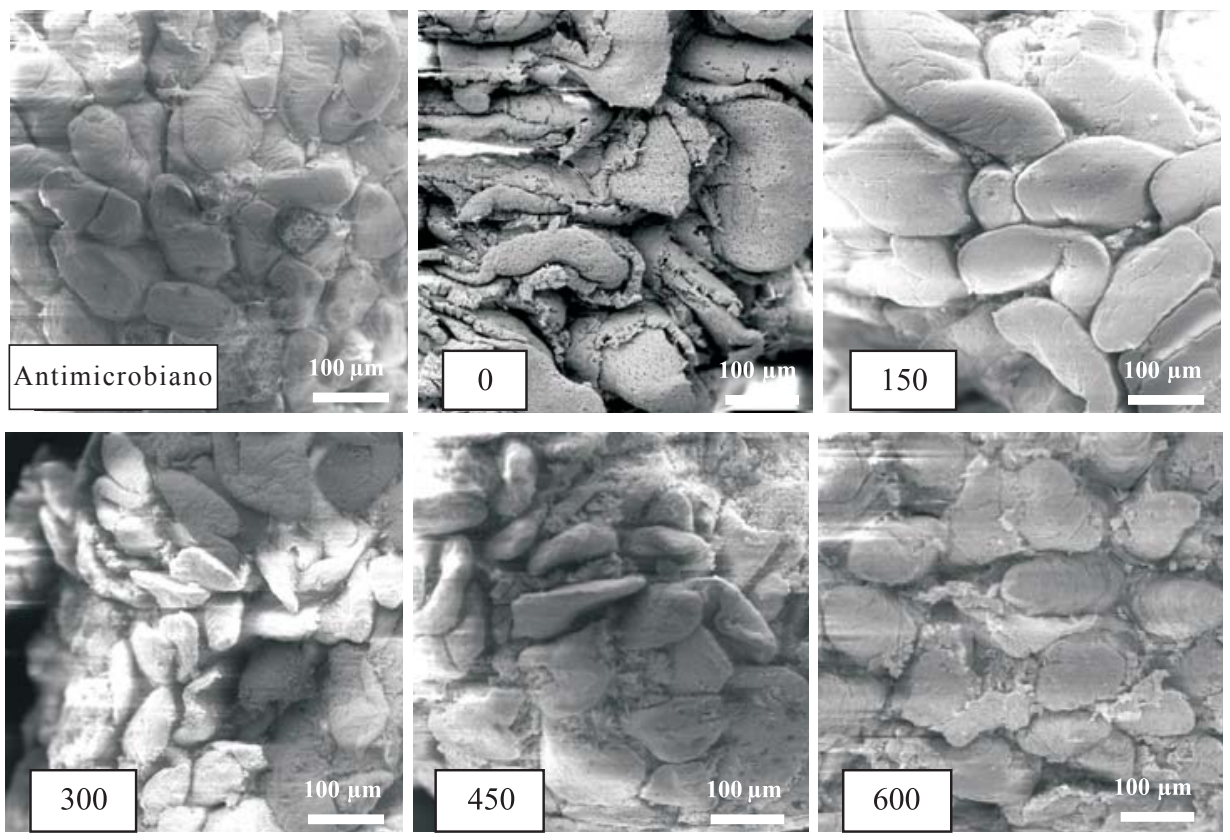

Figura 2 - Eletronmicrografia de varredura do jejuno dos leitões alimentados com dietas contendo antimicrobiano e 0, 150, 300, 450 ou 600 ppm de nucleotídeos. 


\section{Conclusões}

A adição de nucleotídeos em níveis de até 600 ppm em dietas complexas não melhora o desempenho de leitões recém-desmamados. Por outro lado, os nucleotídeos têm efeitos benéficos na morfometria de órgãos e na histologia do epitélio intestinal dos leitões. Além disso, há indicações de que o nível de $150 \mathrm{ppm}$ propicia ganho de peso similar ao obtido com antimicrobiano.

\section{Agradecimentos}

ICC Industrial Comércio Exportação e Importação Ltda.; Nutron Alimentos Ltda.; INVE Nutrição Animal Ltda.

\section{Referências}

ABREU, M.L.T.; DONZELE, J.L.; FONSECA, C.C. et al. Glutamina, nucleotídeos e plasma suíno em rações de leitões no pós-desmame. In: CONGRESSO DA ASSOCIAÇÃO BRASILEIRA DE VETERINÁRIOS ESPECIALISTAS EM SUÍNOS, 13., 2007, Florianópolis. Anais... Florianópolis: EMBRAPA, 2007. (CD-ROM).

AMORIM, H.V.; LOPES, M.L. Tecnologia sobre processamento de leveduras vivas, inativas e seus derivados: conceitos básicos. In: CONGRESSO INTERNACIONAL SOBRE USO DA LEVEDURA NA ALIMENTAÇÃO ANimAl, 1., 2009, Campinas. Anais... Campinas: CBNA, 2009. p.5-20.

ARAÚJO, L.F.; JUNQUEIRA, O.M.; LOPES, E.L. et al. Utilização da levedura desidratada (Saccharomyces cerevisiae) para leitões na fase inicial. Ciência Rural, v.36, p.1576-1581, 2006.

BARBALHO, R.L.C. Suplementação de levedura hidrolisada (Hilyses ${ }^{\circledR}$ ) nas dietas de frangos de corte. 2009. 59f. Dissertação (Mestrado em Zootecnia) - Faculdade de Zootecnia e Engenharia de Alimentos/Universidade de São Paulo, Pirassununga.

BELLAVER, C. O uso de microingredientes (aditivos) na formulação de dietas para suínos e suas implicações na produção e na segurança alimentar. In: CONGRESSO MERCOSUL DE PRODUÇÃo SUÍnA, 2000, Buenos Aires. Anais... Buenos Aires: EMBRAPA, 2000. p.93-108.

BOLELI, I.C.; MAIORKA, A.; MACARI, M. Estrutura funcional do trato digestório. In: MACARI, M.; FURLAN, R.L.; GONZALES, E. Fisiologia Aviária aplicada a frangos de corte. Jaboticabal: FUNEP/UNESP, 2002. p.75-95.

BUDIÑO, F.E.L.; THOMAZ, M.C.; KRONKA, R.N. et al. Influência da adição de probiótico e/ou prebiótico em dietas de leitões desmamados sobre as atividades das enzimas digestivas e parâmetros sanguíneos. Acta Scientiarum.Animal Science, v.26, n.4, p.529-536, 2004.

BUENO, J.; TORRES, M.; ALMENDROS, A. et al. Effect of dietary nucleotides on small intestinal repair after diarrhea. Histological and ultra structural changes. Gut, v.35, p.926-933, 1994.

BUTOLO, J.E. Ingredientes de origem vegetal. In: Qualidade de ingredientes na alimentação animal. Campinas: CBNA, 2002. p.93-238.

CARVER, J.D. Dietary nucleotides: cellular immune, intestinal and hepatic system effects. The Journal of Nutrition, v.124, p.144-148, 1994

CASTILHO, W.; KRONKA, R.N.; PIZAURO JUNIOR, J.M. et al. Efeito da substituição do farelo de soja pela levedura (Saccharomyces cerevisiae) desidratada como fonte protéica em dietas para leitões desmamados sobre peso de órgãos digestivos e atividade das enzimas pancreáticas. Archivos Latinoamericanos de Produccion Animal, v.12, p.12-20, 2004.
CERA, K.R.; MAHAN, D.C.; CROSS, R.F. et al. Effect of age, weaning and postweaning diet on small intestinal growth and jejunal morphology in young swine. Journal of Animal Science, v.66, p.574-584, 1988

COSTA, L.F. Leveduras na nutrição animal. Revista Eletrônica Nutritime, v.1, n.1, p.1-6, Disponível em: <http://www.nutritime. com.br/arquivos_internos/artigos/001V1N1P01_06_JUL2004.pdf.> Acesso em: 22/9/2009.

COSTA, L.B.; TSÉ, M.L.P.; MIYADA, V.S. Extratos vegetais como alternativas aos antimicrobianos promotores de crescimento de leitões recém-desmamados. Revista Brasileira de Zootecnia, v.36, n.3, p.589-595, 2007.

COSTA, L.B. Aditivos fitogênicos e butirato de sódio como potenciais promotores de crescimento de leitões recémdesmamados. 2009. 96f. Tese (Doutorado em Agronomia) Escola Superior de Agricultura "Luiz de Queiroz"/Universidade de São Paulo, Piracicaba.

GARCIA, A. Nucleotídeos como potenciais promotores do crescimento de leitões recém-desmamados. 2007. $40 \mathrm{f}$. Dissertação (Mestrado em Agronomia) - Escola Superior de Agricultura "Luiz de Queiroz"/Universidade de São Paulo, Piracicaba.

GOMES, F.E.; FONTES, D.O.; SALIBA, E.O.S. et al. Ácido fumárico e sua combinação com os ácidos butírico ou fórmico em dietas de leitões recém-desmamados. Arquivo Brasileiro de Medicina Veterinária e Zootecnia, v.59, n.5, p.1270-1277, 2007.

GOMES, J.D.F.; PUTRINO, S.M.; MARTELLI, M.R. et al. Morfologia de órgãos digestivos e não digestivos de suínos de linhagens modernas durante as fases de crescimento, terminação e pós-terminação. Acta Scientiarum Animal Science, v.29, n.3, p.261-266, 2007.

GRIMBLE, G.K. Dietary nucleotides and gut mucosal defence. Gut, v.35, p.46-51, 1994.

JIN, L.; REYNOLDS, L.P.; REDMER, D.A. et al. Effects of dietary fiber on intestinal growth, cell proliferation, and morphology in growing pigs. Journal of Animal Science, v.72, p.2270-2278, 1994.

LANDELL FILHO, L.C., KRONKA, R.N., THOMAS, M.C. Utilização da levedura de centrifugação da vinhaça (Saccharomyces cerevisiae) como fonte de proteína para leitões na fase inicial (10 a $30 \mathrm{~kg}$ PV). Revista Brasileira de Zootecnia, v.23, n.2, p.283-291, 1994.

MARIBO, H. Weaning pigs without antibiotic growth promoters: strategies to improve health and performance. In: NUTRITIONAL BIOTECHNOLOGY IN THE FEED AND FOOD INDUSTRIES, 19., 2003, Lexington, Anais... Lexington: Nottingham University Press, 2003. p.179-184.

MATEO, C.D.; PETERS, D.N.; STEIN, H.H. Nucleotides in sow colostrum and milk at different stages of lactation. Journal of Animal Science, v. 82, p.1339-1342, 2004.

MENTEN, J.F.M.; MIYADA, V.S. Effects of antimicrobial feed additives, alone or in combination on weanling pigs. In: ANNUAL MEETING - AMERICAN SOCIETY OF ANIMAL SCIENCE, 1995, Orlando. Proceedings... Illinois: American Society of Animal Science, 1995. p.174.

NUNES, J.R.V. Uso de levedura de cana (Saccharomyces cerevisiae) na alimentação inicial de leitões. In: REUNIÃO ANUAL DA SOCIEDADE BRASILEIRA DE ZOOTECNIA, 24., 1988, Brasília. Anais... Brasília: Sociedade Brasileira de Zootecnia, 1988. p.18.

OETTING, L.L.; UTIYAMA, C.E.; GIANI, P.A. et al. Efeitos de extratos vegetais e antimicrobianos sobre a digestibilidade aparente, o desempenho, a morfometria dos órgãos e a histologia intestinal de leitões recém-desmamados. Revista Brasileira de Zootecnia, v.35, n.4, p.1389-1397, 2006.

OLIVEIRA JUNIOR, A.R. Glutamina, ácido glutâmico e ou extrato de levedura na dieta de leitões desmamados. 2008. 52f. Dissertação (Mestrado em Ciências Veterinárias) Faculdade de Medicina Veterinária/Universidade Federal de Uberlândia, Uberlândia. 
PELÍCIA, V.C.; SARTORI, J.R.; ZAVARIZE, K.C. et al. Effect of nucleotides on broiler performance and carcass yield. Brazilian Journal of Poultry Science, v.12, n.1, p.31-34, 2010.

PEDRoso, A.A; OETTING, L.L.; UTIYAMA, C.E. et al. Variabilidade espacial da comunidade bacteriana intestinal de suínos suplementados com antibióticos ou extratos herbais. Revista Brasileira de Zootecnia, v.34, n.4, p.1225-1233, 2005 .

PLUSKE, J.R.; HAMPSON, D.J.; WILLIAMS, I.H. Factors influencing the structure and function of the small intestine in the weaned pig: a review. Livestock Production Sciences, v. 51, p.215-236, 1997.

RAO, D.S.; McCRACKEN, K.J. Energy: protein interactions in growing boars of high genetic potencial for lean growth: I effects on growth, carcass characteristics and organ weights. Animal Production, v.54, n.1, p.75-82, 1992.

RAVINDRAN, V.; KORNEGAY, E.T. Acidification of weaner pig diets: a review. Journal of the Science of Food and Agriculture, v.62, p.313-322, 1993.

RIZZO, P.V.; MENTEN, J.F.M.; RACANICCI, A.M.C. et al. Extratos vegetais em dietas para frangos de corte. Revista Brasileira de Zootecnia, v.39, n.4, p.801-807, 2010.

ROSTAGNO, H.S.; ALBINO, L.F.T.; DONZELE, J.L. et al. Tabelas brasileiras para aves e suínos: composição de alimentos e exigências nutricionais. 2.ed. Viçosa, MG: Universidade Federal de Viçosa, 2005. 186p.

RUTZ, F.; ANCIUTI, M.A.; RECH, J.L. et al. Desempenho e características de carcaças de frangos de corte recebendo extrato de leveduras na dieta. Ciência Animal Brasileira, v.7, p.349-355, 2006.

SANTOS, M.W.; COSTAGNA, A.A.; SANTANA, J. et al. A levedura seca como fonte de proteína para leitões em recria. In: REUNIÃO ANUAL DA SOCIEDADE BRASILEIRA DE ZOOTECNIA, 25., 1988, Viçosa, MG. Anais... Viçosa, MG: Sociedade Brasileira de Zootecnia, 1988. p.58.

SILVA, E.N. Antibióticos intestinais naturais: bacteriocinas. In: SIMPÓSIO SOBRE ADITIVOS ALTERNATIVOS NA NUTRIÇÃO ANIMAL, 2000, Campinas. Anais... Campinas: Colégio Brasileiro de Nutrição Animal, 2000. p.15-24.

SILVA, C.A.; ROCHA, F.L.; MACHADO, G.S. et al. Edulcorante na água de consumo e efeitos sobre o desempenho e o desenvolvimento da mucosa intestinal de leitões submetidos ao desmame precoce segregado. Revista Brasileira de Zootecnia, v.29, p.1770-1776, 2000.

STATISTICAL ANALYSIS SYSTEM - SAS. User's guide statistics. Cary: 2001. 155p.

STEIN, H.H.; KIL, D.Y. Reduced use of antibiotic growth promoters in diets fed to weanling pigs: dietary tools, part 2. Animal Biotechnology, v.17, p.217-231, 2006.

TIBBETTS, G.W. Nucleotides from yeast extract: potential to replace animal protein sources in food animal diets. In: ANNUAL SYMPOSIUM OF NUTRITIONAL BIOTECHNOLOGY IN THE FEED AND FOOD INDUSTRIES, 18., 2002, Lexington. Anais... Lexington: Nottingham University Press, 2002. p. 435-443.

TUCCI, F.M.; THOMAZ, M.C.; KRONKA, R.N. et al. Efeitos da adição de agentes tróficos na dieta de leitões desmamados sobre a ultra-estrutura do intestino delgado. In: REUNÃO ANUAL DA SOCIEDADE BRASILEIRA DE ZOOTECNIA, 41., 2004, Campo Grande. Anais... Campo Grande: SBZ, 2004. (CD-ROM).

UAUY, R.; STRIGEL, G.; THOMAS, R. et al. Effect of dietary nucleosides of growth and maturation of the developing gut in rat. Journal of Pediatric Gastroenterology and Nutrition, v.10, n.4, p.497-503, 1990.

UAUY, R.; QUAN, R.; GIL, A. Role of nucleotides in intestinal development and repair: implications for infant nutrition. The Journal of Nutrition, v.124, p.1436-1441, 1994.

VEUM, T.L.; BOWMAN, G.L. Saccharomyces cerevisiae yeast culture in diets for mechanically-fed neonatal piglets and early growing self-fed pigs. Journal of Animal Science, v.37, p.67-71, 1973.

VIOLA, E.S.; VIEIRA, S.L. Ácidos orgânicos e suas misturas em dietas de suínos. In: SIMPÓSIO SOBRE MANEJO E NUTRIÇÃO DE AVES E SUÍNOS, 2003, Campinas. Anais... Campinas: Colégio Brasileiro de Nutrição, 2003. p.255-284.

WITTE, D.P.; WIGINTON, D.A.; HUTTON, J.J. et al. Coordinate developmental regulation of purine catabolic enzyme expression in gastrointestinal and post implantation reproductive tracts. Journal of Cell Biology, v.115, n.1, p.179-190, 1991.

YU, I.T.; WU, J.F.; YANG, P.C. et al. Roles of glutamine and nucleotides in combination in growth, immune responses and FMD antibody titres of weaned pigs. Journal of Animal Science, v.75, p.379-385, 2002. 